\title{
Noise Pollution Mapping Using GIS in Nairobi, Kenya
}

\author{
Enock Abe Wawa, Galcano Canny Mulaku \\ Department of Geospatial and Space Technology, University of Nairobi, Nairobi, Kenya \\ Email: wawabenock@gmail.com, gmulaku@yahoo.com
}

Received 17 August 2015; accepted 10 October 2015; published 13 October 2015

Copyright (C) 2015 by authors and Scientific Research Publishing Inc.

This work is licensed under the Creative Commons Attribution International License (CC BY). http://creativecommons.org/licenses/by/4.0/

c) (i) Open Access

\begin{abstract}
Noise is any sound that causes physiological uneasiness to the ear. People in many environments today, especially urban ones, are exposed to such noise without realizing its potential danger to their healthy hearing. This situation is largely contributed to by the little attention that most governments, especially in the developing countries, pay to noise as a pollution issue. This paper describes a study that aimed at measuring the noise levels at selected points in Nairobi's CBD with a view to generate a noise map over the study area in addition to identifying areas of high noise intensity or noise hot spots. The study found that noise levels, on average, varied from $61 \mathrm{db}$ to 78 $\mathrm{db}$, increasing from the west to the east of the CBD, and emanated mainly from vehicular traffic; several noise hotspots were also identified, and they are located mainly to the east of the CBD. The paper concludes that although the study was not city-wide, the noise levels observed are high enough to warrant further research and action by the environmental authorities.
\end{abstract}

\section{Keywords}

Noise Pollution, Hot Spots, Nairobi, Kenya

\section{Introduction}

Environmental pollution and its concentration are significantly increasing and are causing a global threat to the quality of the environment and the fragile ecosystem of the Earth. Management of environmental pollution is a challenge in itself; air, water, hazardous waste and noise pollution are now serious concerns in many nations.

One of the serious and most often overlooked issues about environmental pollution is environmental noise. Noise is seen as a normal phenomenon. Action plans and subsequent acoustical planning are not seriously considered in many parts of the world. As a result, the impact of noise is not well understood.

It is important to measure the level of noise emanating from specified sources and to share such information 
with the people that are at the noise source. This will help the public to realize the levels of noise that they are exposed to and to develop mechanisms for reducing the noise to permissible levels [1]. A geographic information system (GIS) is a computer based information system that enables the input, management, analysis, output and dissemination of spatially referenced, land related data and information at all scales [2]. Noise maps provide good spatial presentations of acoustic situations. GIS provides good visualization tools of noise propagation and assists in building a spatial decision support system that can be used in the decision making process. Noise maps built in GIS can therefore be used for such analysis and management processes.

Since noise has some psychological and social implications and affects the well-being and quality of life in our environment, there is a need for noise to be visualized and shown especially to affected parties. GIS can facilitate such display and visualization and can lead to findings which might be necessary to inform infrastructure planning, ensure productivity in various places of work or study, and to implement or enforce compliance to any existing noise regulations.

\section{Noise and Noise Mapping}

\subsection{Sound and Noise}

Environmental noise pollution continues to pose a significant threat to human health and the quality of life for millions of people worldwide. Urbanization and associated growth in mobility and industrialization have resulted in the intensification of noise in densely populated areas causing an increase in noise exposure. As the population increases in an urban area, industrial activities also increase to meet people's needs. This results in increased noise levels.

In order to understand what noise and thus noise pollution is, it is first vital to understand what sound is, how it is produced and how it consequently becomes noise.

In physics, sound is defined as vibration that propagates as a typically audible mechanical wave of pressure and displacement through a medium such as air or water. In physiology, sound is the reception of such waves and their perception by the brain. When an object moves or vibrates in the air, it creates waves which spread out away from the source. These vibrations radiate out in all directions from the source like ripples in a pond and create pressure changes which are detected by the human ear. These small changes in air pressure are relayed to the brain and are interpreted as sounds. Such changes in air pressure are very small in comparison to the barometric air pressure that surrounds us all the time.

Sound is measured using a Sound Level Meter, also referred to as a noise meter or a decibel meter in Decibels $(\mathrm{dB})$ or in Pascal units.

Sound starts becoming noise when it causes uneasiness to the ear. The human ear can hear sounds from the quietest source (e.g. a sleeping dog) to the highest source (e.g. a jet aircraft taking off). The lowest pressure change that can generally be detected by the human ear is $0 \mathrm{~dB}$ (0.00002 Pascal). The pressure change that represents the threshold of pain to the human ear is about $140 \mathrm{~dB}$ (200 Pascal), equivalent to the sound of a jet aircraft.

Noise is therefore any undesirable sound that is intrinsically objectionable or that may cause adverse effects on human health or the environment [1]. In the simplest of terms, noise is defined as "unwanted sound". Noise pollution is a term which refers to the level of ambient sound that is potentially aggravating or annoying to human beings and even to animals.

\subsection{The Impact of Noise}

Noise pollution has many negative physiological and social implications and affects the well-being and quality of life in our environment.

Noise pollution disturbs sleep, increases stress, causes distraction, discomfort and deprives peace of mind. It disturbs students, is a hazard to the aged and the sick and is a sign of disrespect to the community at large. Long exposure to noise can cause noise-induced hearing loss. High noise levels can also contribute to cardiovascular effects [3].

Noise can have detrimental effects on animals too, for instance, scaring animals out of their natural habitats. Other minor psychological problems such as tension, irritability and difficulty in concentrating are also evident from noise. 
When having prolonged exposure, noise will have far-reaching detrimental effects; moreover, coupled with the increasingly urbanised environment characterized by a high density of living in high-rise residences, the capability of noise pollution to affect a larger proportion of people also increases; quality of life is also undermined, especially during night-time. Other negative impacts that are related to the quality of life include undue alterations in the everyday behaviour of individuals; examples include preventing the use of residential areas such as balconies and common areas due to excessive noise levels as well as the shutting of windows in homes to prevent noise emission [4].

\subsection{Noise Mapping}

Noise mapping is the measurement of sound levels at pre-determined points and the use of the resulting data to construct a graphic representation of the distribution of sound levels over a given region for a defined period. Noise maps can be used to assess conformance to allowable noise levels, set up noise reduction measures and monitor the impact of such measures.

1) Noise mapping in developed countries

In developed countries, problems with noise are often rated at the highest level of concern together with issues such as global warming. Within the context of an emerging evidence base suggesting links between exposure to environmental noise and public health concerns, noise policy gained greater prominence in EU environmental policy throughout the 1990s [5]. In June 2002, the European Parliament adopted Directive 2002/49/EC (END), relating to the assessment and management of environmental noise [6]. The aim of this directive was to define a common approach intended to avoid, prevent or reduce the harmful effects of environmental noise.

2) Noise mapping in developing countries

Noise is one of the most unregulated and overlooked forms of pollution as it is temporal and inconspicuous. It does not have any immediate observable effect and it doesn't cause direct impact upon individuals [7]. Many cities in developing countries are now having to take action to enhance their institutional and technical capabilities to monitor and control noise exposure and implement preventive actions in order to reduce the risks that noise poses to their citizens. The severity of environmental noise in cities of developing countries reflects the level and speed of development. As cities undergo economic and industrial development, environmental noise becomes an increasing problem.

Many people in developing countries suffer the pressure of a combination of different driving forces like motorization, industrialization and an increase in urban population density. Most of the cities in such countries are however without the well-developed civil infrastructure and financial resources to control these forces. The result is that the capacity of many cities to cope with the combined pressures is often exceeded leading to a deterioration in environmental quality and human livelihood.

As compared to developed countries, problems with noise in developing countries are often not rated at the highest level of concern. The link between noise and human health is not taken seriously and hence there is not much done to curb the emission of noise.

3) Noise mapping in Kenya

As the population increases within various towns and urban areas in Kenya, industrial activities also increase to meet people's needs resulting in increased noise levels. Poor land use planning and increased traffic levels have also contributed to the elevation of noise levels in such areas.

It is also necessary to note that in order to meet spiritual needs of the people, churches, mosques and temples are continuously being established in many areas. Religious activities have the potential for noise pollution due to the use of loud speakers in the spread of their messages.

To protect the human population and other organisms that are sensitive to noise, monitoring of noise levels has become an invaluable management tool. It is thus necessary to provide every Kenyan with a safe and secure environment as provided for in the Kenyan constitution which stipulates a right to a clean and safe environment as a fundamental human right of the people of Kenya.

Nairobi, being the capital of Kenya, has a high concentration of industrial activities that has attracted a population of over three million people. To promote harmonious coexistence between different land uses, it is important to manage externalities generated by diverse land uses meant to meet a wide array of needs. Nairobi has doubled its population in the last decade and Kenya's urban population currently stands at about 40 per cent of the national population [8]. 
In Kenya, the impact of noise is not yet taken seriously and its effects are not well emphasized. The link between noise and human health is also not taken seriously and hence there is not much done to curb the emission of noise or to better understand its spread and effects.

\section{The Nairobi Study}

\subsection{The Study Area}

The area of study, as shown in Figure 1, is a part of the CBD of Nairobi County in the Republic of Kenya between latitudes $1^{\circ} 09^{\prime} 56^{\prime \prime}$ and $1^{\circ} 27^{\prime} 28^{\prime \prime}$ South and longitudes $36^{\circ} 39^{\prime} 04^{\prime \prime}$ and $37^{\circ} 06^{\prime} 18^{\prime \prime}$ East. Nairobi County borders Kiambu, Machakos and Kajiado Counties and has an approximate area of 684 square kilometres with an approximate population of 3.36 million people [9]. Therefore it has an average population density of 4850 people per square kilometre. The study area in the CBD is approximately 1.776842 square kilometres.

There are many commercial activities, industrial sites, institutional, recreational and residential areas within Nairobi ranging from small scale retail, sales, services and businesses to large companies with offices, warehouses and go downs; slum housing and informal settlement to extremely lavish housing; mixed commercial-institutional and mixed residential-commercial land use and some few open spaces without any development.

Nairobi is the world's fourth most congested city according to a 2011 survey. Infrastructure has been made obsolete by a growing population that is keen on cars. Much of Nairobi's road network is more than half a century old and was developed for just 350,000 inhabitants; since then Nairobi's population has swelled and like many other African cities it cannot build roads as fast as its residents can buy cars. According to an IBM study, approximately 400 new vehicles arrive on the streets each day. Figure 2 shows a close up of the study area.

\subsection{Study Objectives}

Generally, the study aimed at sampling, documenting and spatially analyzing noise levels in the Nairobi Central Business District.

Specifically, it aimed to:

- measure noise levels from predetermined potential sources of noise.

- develop a 2D strategic noise map for the CBD and to identify noise "hot spots" therein based on noise levels.

\subsection{Methodology}

The relevant data sets identified for collection included noise data, roads data, and buildings data in the CBD.
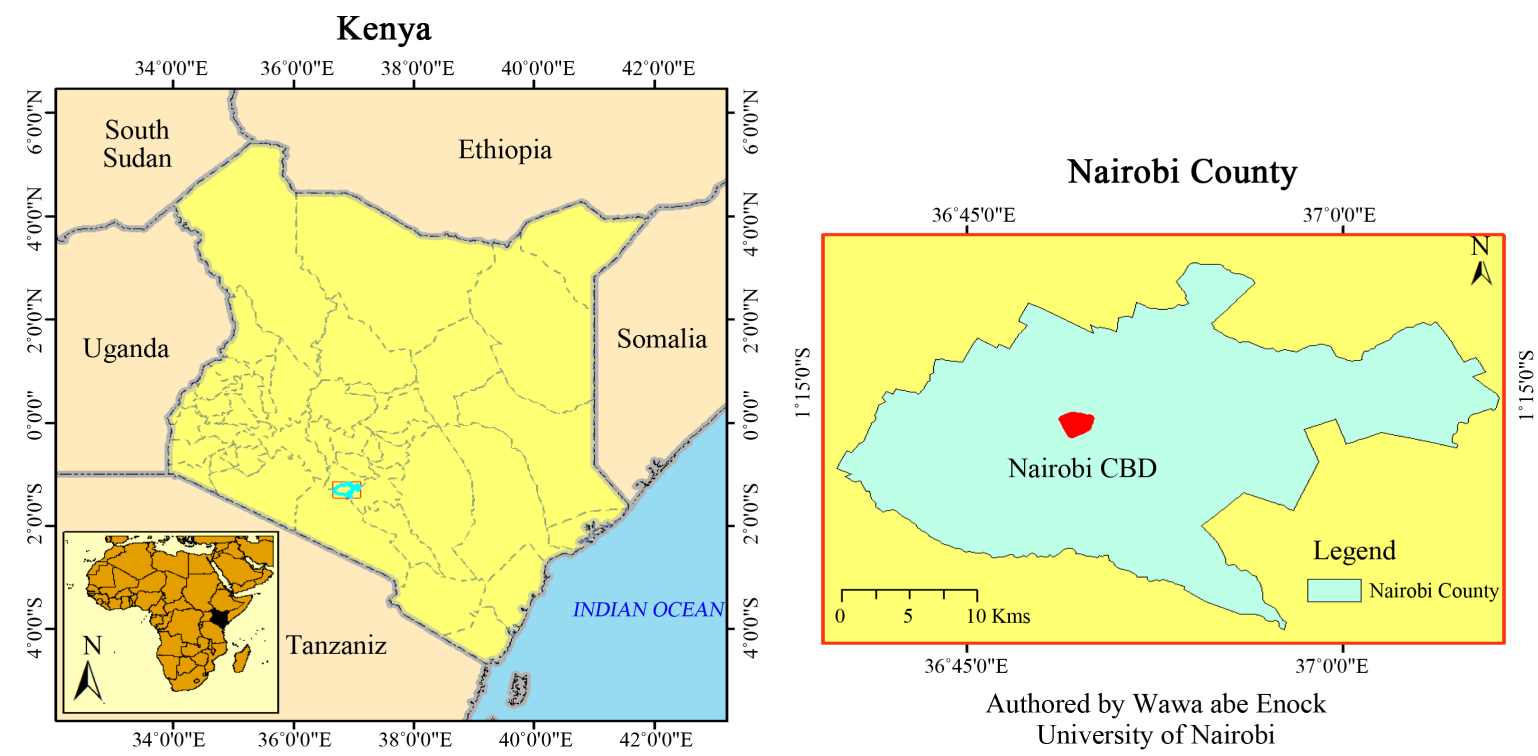

Figure 1. Location of the study area. 


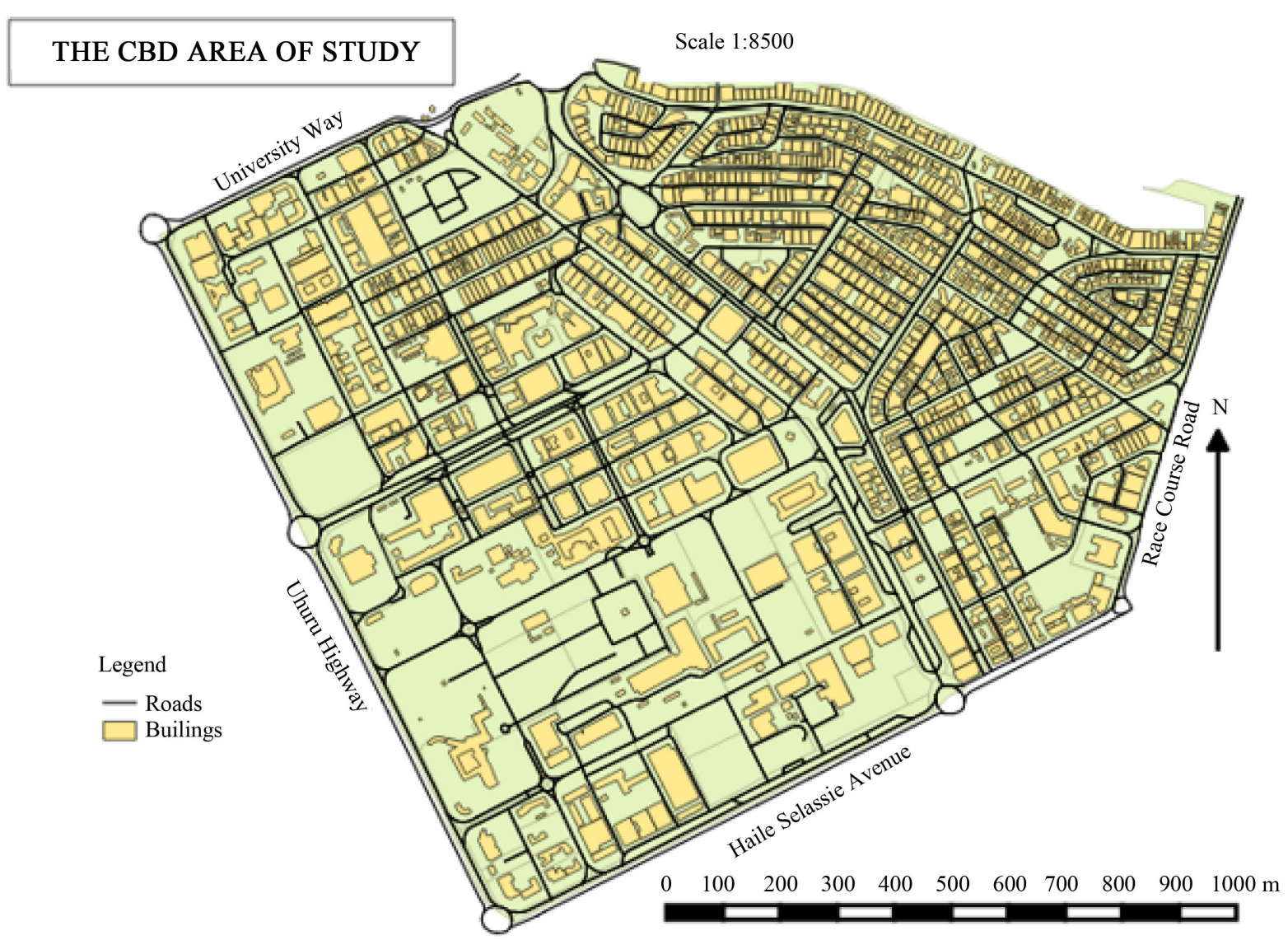

Figure 2. The study area in the CBD.

The noise data used in this study was obtained from field measurements in the area of study using a sound level meter and a hand held GPS. Coordinates were taken concurrently with readings upon sampling site visits. LAeq, which refers to equivalent continuous noise level, is a single decibel value derived from measurements taken in a period of time to account for fluctuations. This data was recorded in data sheets.

The roads data was obtained on-line, created and prepared jointly by the Japan International Cooperation Agency (JICA) and the Government of the Republic of Kenya under the Japanese Government Technical Cooperation Program. The roads file was created with the intention of providing a freely accessible, generalized representation of Nairobi's transportation network; a freely available dataset that will allow those interested in Nairobi's future to use GIS to make informed decisions. The roads data was then updated by digitizing from Open Streets Maps.

The data on buildings within the CBD was also obtained online, created and prepared jointly by the Japan International Cooperation Agency (JICA) and the Government of the Republic of Kenya under the Japanese Government Technical Cooperation Program.

This study was done over a short period of time and specifically during the day due to constraints of time, security and cost to show a GIS-based approach for 2D noise modeling. Coupled with other constraints, the sampling duration was less than 1 minute at every sampling point. The temporal dimension was not considered as measurements were not taken concurrently but individually and momentarily. This methodology is summarized in Figure 3.

\subsection{Results}

Figure 4 shows the Nairobi CBD noise map, probably the first ever constructed, and which is the key result that was obtained from mapping average noise within the CBD. Figure 5 shows the average recorded noise levels, while Figure 6 shows the principal noise sources in the study area. 


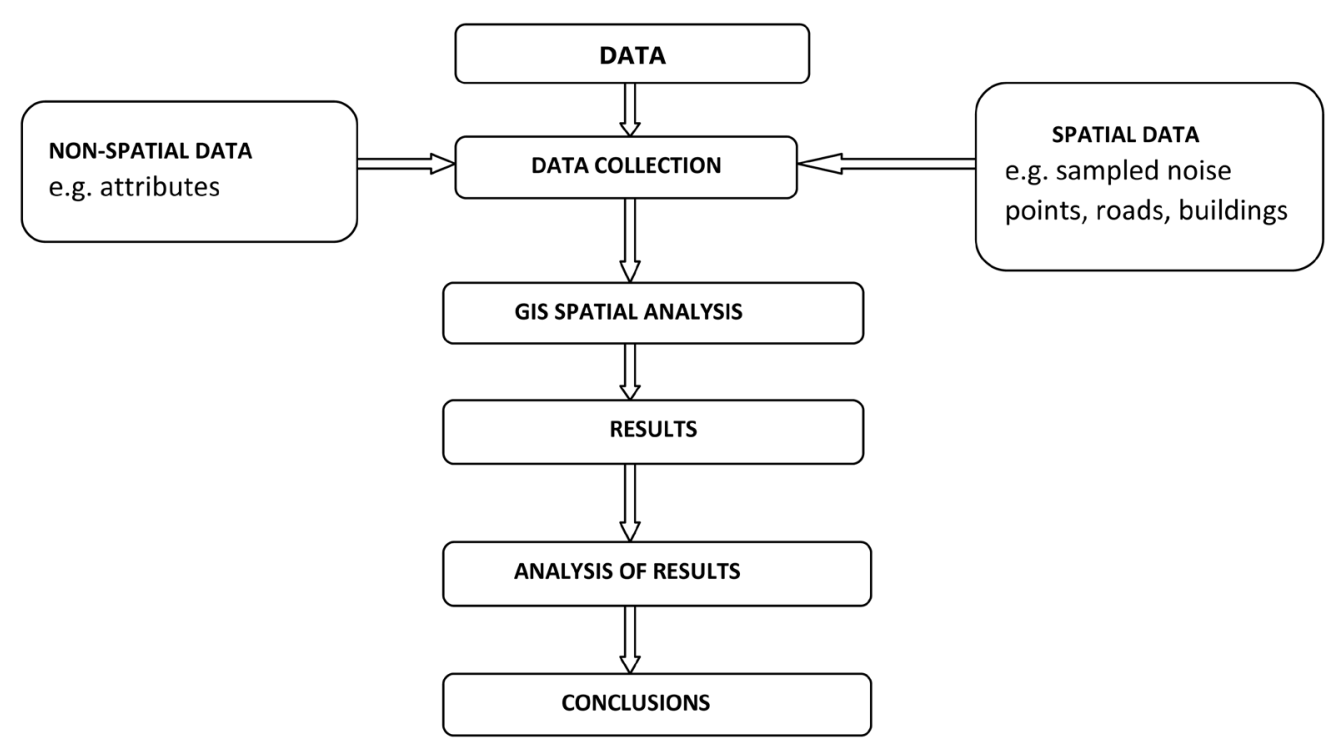

Figure 3. Flow chart of methodology.

THE CBD AREA OF STUDY

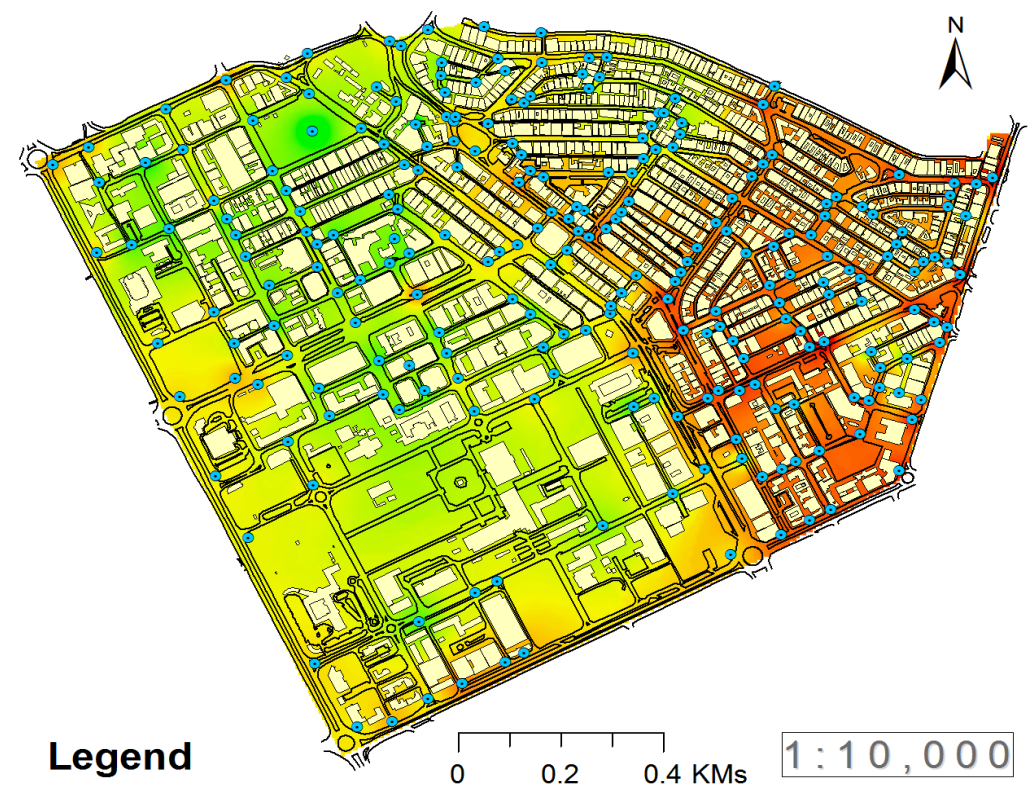

- Noise Sampling Sites
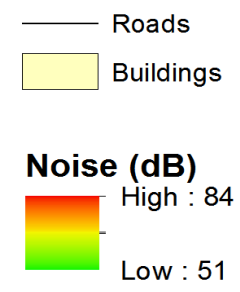

Authored by Wawa Abe Enock f19/1474/2010

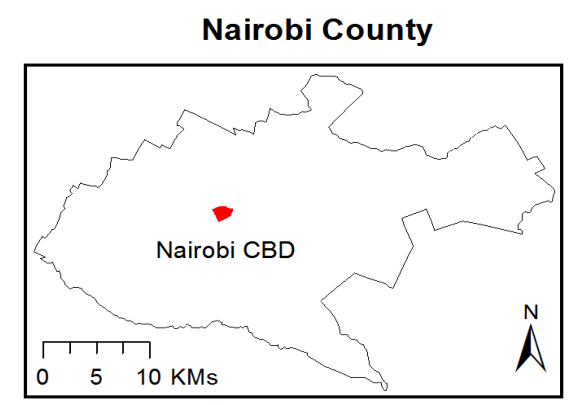

Figure 4. Nairobi CBD noise map. 


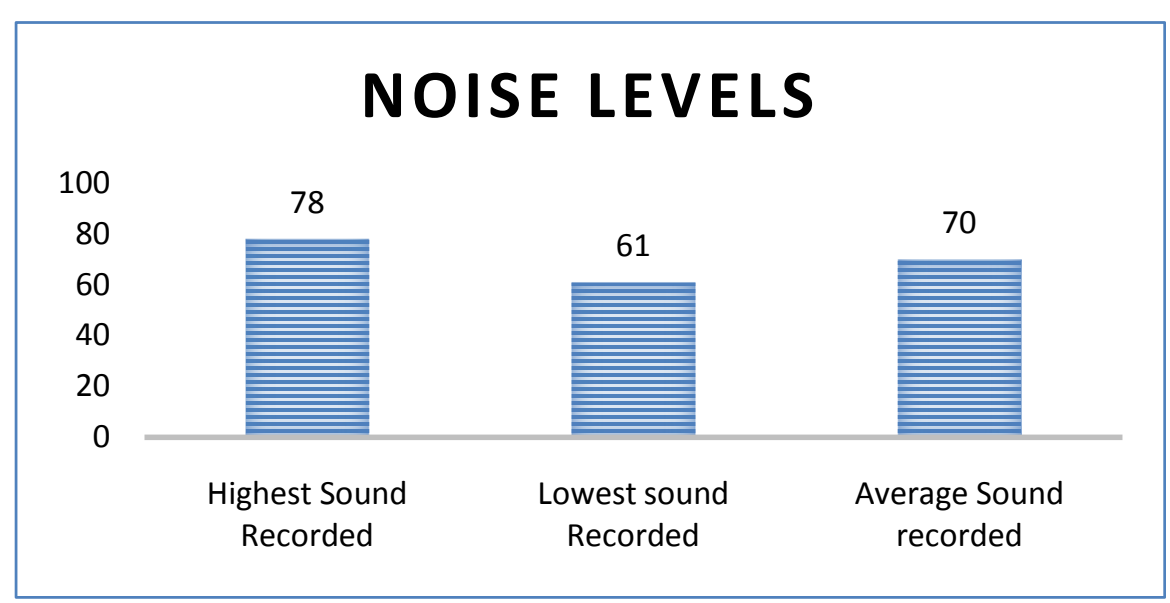

Figure 5. The average recorded noise levels.

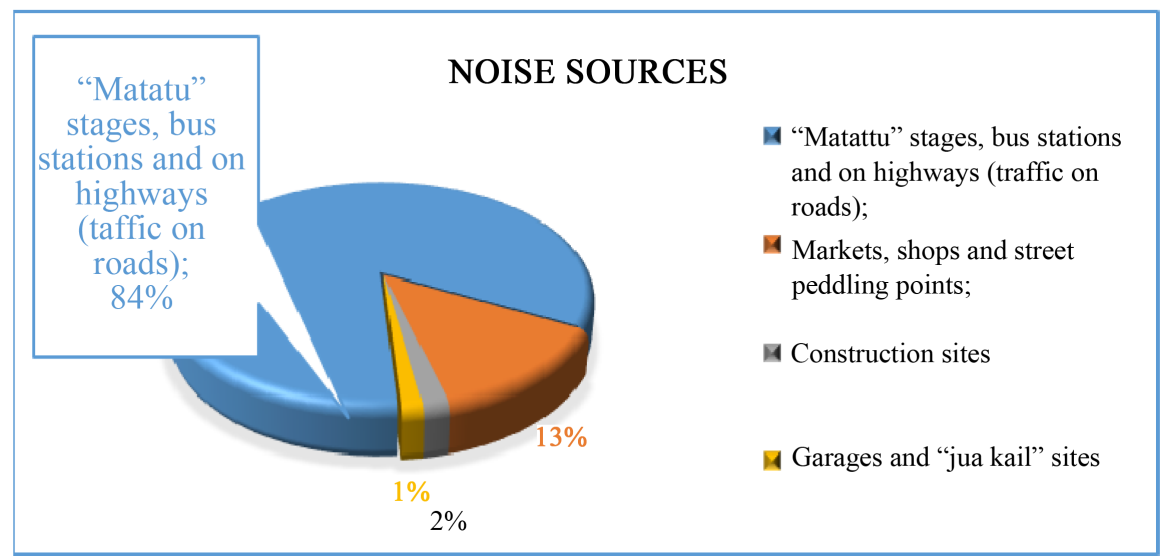

Figure 6. Principal noise sources in the CBD.

A 2D strategic noise map showing noise "hot-spots" in the study area was also developed to show the noisiest areas in the CBD based on noise levels, as illustrated in Figure 7.

\subsection{Discussion}

The results show that the eastern parts of Nairobi's CBD have the highest levels of noise. This can be attributed to a high concentration of matatu (public service vans) stops and open air vendors in that part of the CBD. Figure 6 also shows that by far, the greatest source of noise in the CBD is traffic. This is consistent with the results of some studies that have been carried out elsewhere, such as Gholami et al. (2012); consequently, any mitigation measures would have to focus on this source. The highest sound recorded, at $78 \mathrm{db}$, shows that in some parts, especially the hotspots, the noise levels approach the healthy hearing limit of about $85 \mathrm{db}$ [10]. In interpreting these results, one must keep in mind that the study was limited to only the CBD and would need rolling out to the other parts of the city in order to get results more representative of the whole city; in addition, noise levels, especially from traffic, are bound to vary with time of day or night and therefore continous noise recording would give even more representative results.

\section{Conclusion}

The paper has presented the results of a noise mapping study in Nairobi city, focusing on the CBD. The study found that the CBD noise levels vary from a low of $61 \mathrm{db}$ in the west to a high of $78 \mathrm{db}$ in the east and that most of the noise can be attributed to vehicular traffic. These results indicate that noise levels in Nairobi are high enough to warrant the attention of the environmental authorities and further research. An extension of this study 


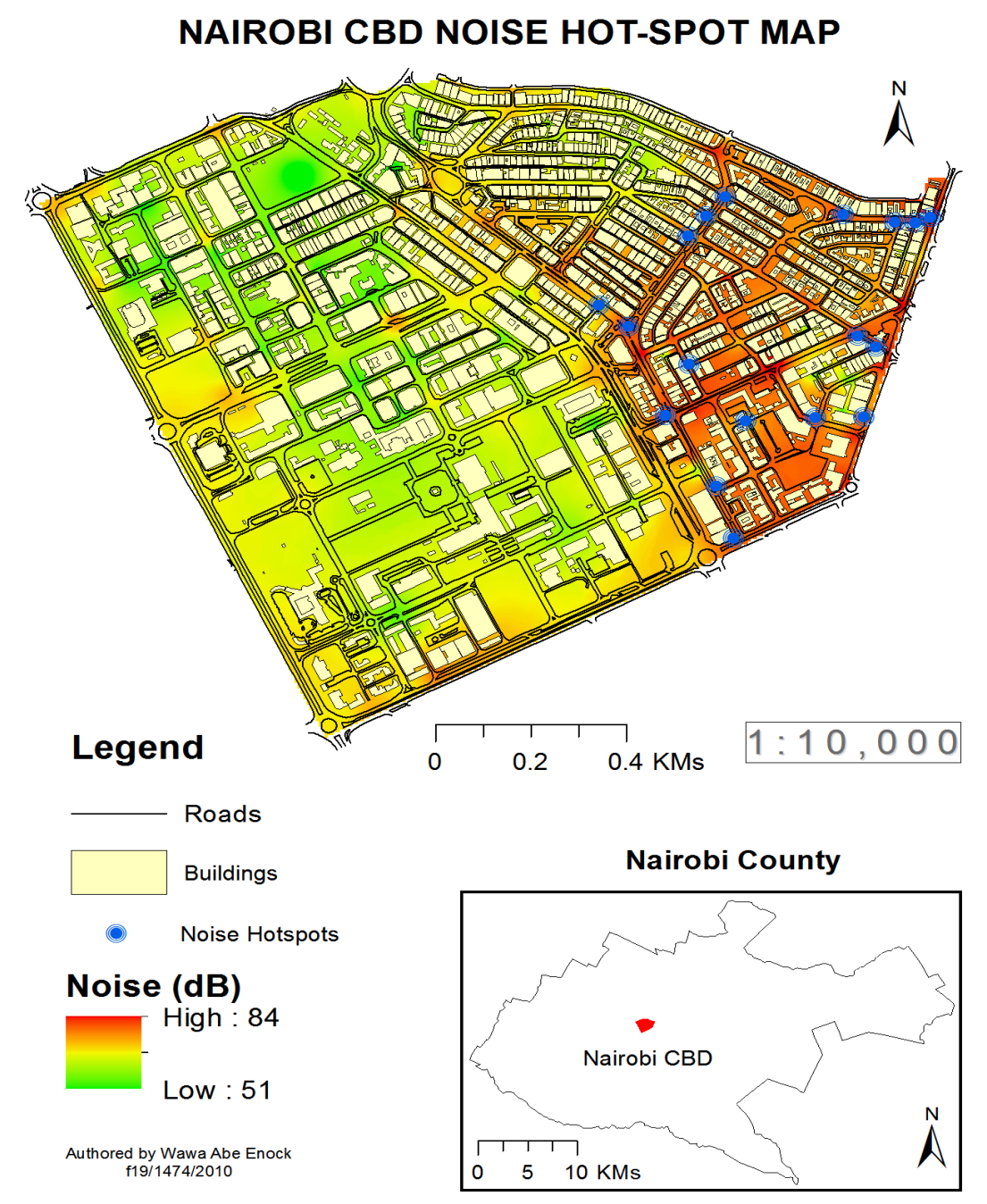

Figure 7. Nairobi CBD noise hot-spot map.

to cover the whole city, with noise levels observed at variant times, would be a recommended way forward.

\section{References}

[1] Government of Kenya (1999) The Environmental Management and Coordination Act. Laws of Kenya.

[2] Mulaku, G.C. (2000) Setting up a Land Information System: A Systematic Approach. South African Journal of Surveying and Geoinformation, 1, 260-264.

[3] WHO (2009) Night Noise Guidelines for Europe. World Health Organization, Geneva, Chapter 4, 61-77.

[4] Berglund, B., Lindvall, T. and Schwela, D. (1999) Guidelines for Community Noise. World Health Organisation, Geneva, 121.

[5] EU (1993) The Fifth Environmental Action Programme of the EU. Official Journal of the European Communities, No. C 138.

[6] EU (2002) The European Union Directive 2002/49/EC of the European Parliament and the Council. Official Journal of the European Communities.

[7] Gholami, A., Parvin, N., Monazzam, M., Alireza, G., Monavvari, S. and Ali, A. (2012) Evaluation of Traffic Noise Pollution in a Central Area of Tehran through Noise Mapping in GIS. Advances in Environmental Biology, 6, 2365-2371.

[8] Government of Kenya (2008) Kenya Vision 2030: A Globally Competitive and Prosperous Kenya. National Economic and Social Council (NESC), Nairobi.

[9] Government of Kenya (2009) Kenya National Bureau of Statistics Census Report. Volume Ib, 18.

[10] Osha (2015) Website of the Occupational Safety and Health Administration (USA). www.osha.gov 